\title{
Correction to: A 3i hip fracture liaison service with nurse and physician co-management is cost-effective when implemented as a standard clinical program
}

\author{
L. A. Beaupre ${ }^{1}$ - D. Lier ${ }^{2}$ - C. Smith ${ }^{3}$ - L. Evens ${ }^{3}$ - H. M. Hanson ${ }^{4,5}$ - A. G. Juby ${ }^{6}$ - P. Kivi ${ }^{7}$ - S. R. Majumdar ${ }^{2}$. \\ On behalf of the STOP-Fracture Team
}

Published online: 27 August 2020

(C) International Osteoporosis Foundation and National Osteoporosis Foundation 2020

\section{Correction to: Archives of Osteoporosis (2020) 15:113 https://doi.org/1007/s11657-020-00781-w}

The original version of this article, published on 22 July 2020, unfortunately contained a mistake.

Throughout the article, the authors state "anti-absorptive" medication when it should be instead "anti-resorptive" medication.

Publisher's note Springer Nature remains neutral with regard to jurisdictional claims in published maps and institutional affiliations.

The online version of the original article can be found at https://doi.org/ 10.1007/s11657-020-00781-w

\section{A. Beaupre}

lauren.beaupre@ualberta.ca

1 University of Alberta (Physical Therapy), 2-50 Corbett Hall, Edmonton, AB T6G2G4, Canada

2 University of Alberta (Medicine), Edmonton, AB, Canada

3 Alberta Bone and Joint Health Institute, Calgary, AB, Canada

4 Alberta Health Services, Calgary, AB, Canada

5 University of Calgary, Calgary, AB, Canada

6 University of Alberta (Geriatric Medicine), Edmonton, AB, Canada

7 University of Alberta (Family Medicine), Edmonton, AB, Canada 